\title{
Crusted ("Norwegian") scabies in a specialist HIV unit: successful use of ivermectin and failure to prevent nosocomial transmission
}

\author{
Elizabeth L Corbett, Ian Crossley, John Holton, Nicholas Levell, Robert F Miller, \\ Kevin M De Cock
}

A nosocomial outbreak of scabies in a specialist inpatient HIV unit resulted from a patient admitted with crusted scabies. Treatment of his infestation with topical scabicides alone failed and he remained infectious for several weeks. His infestation was then eradicated with combined topical treatment and oral ivermectin. In total, 14 (88\%) out of 19 ward staff became symptomatic, and $4(21 \%)$ had evidence of scabies on potassium hydroxide examination of skin scrapings. The ward infection control policy was changed to distinguish patients with crusted scabies from those with ordinary scabies. A second patient with crusted scabies was treated with combined oral and topical therapy early in his admission and nursed with more stringent isolation procedures. No nosocomial transmission occurred and his infestation responded rapidly to treatment. Patients with crusted scabies require strict barrier nursing if nosocomial transmission is to be avoided. Ivermectin combined with topical scabicides may be a more efficacious treatment than topical scabicides alone in such patients.

(Genitourin Med 1996;72:115-117)

Keywords: Opportunistic infections, dermatology, therapy, scabies

HIVIAIDS Unit

Camden \& Islington

Community Health

Services NHS Trust, The Middlesex

Hospital, Mortimer

Street, London

W1N 8AA

E L Corbett

I Crossley

R F Miller

K M De Cock

Department of

Microbiology,

University College

London Medical

School, London

WC1 6JJ

J Holton

Department of

Dermatology,

University College

London Hospitals,

Middlesex site,

Mortimer Street,

London W1N 8AA

N Levell

Address correspondence to:

Dr E L Corbett, 58 Rainham

Road, London NW10 5DJ,

Accepted for publication 12 November 1995

\section{Introduction}

Scabies is a frequent problem among patients infected with human immunodeficiency virus (HIV). ${ }^{1}$ Patients unable to mount an adequate immune response to the infestation develop atypical rashes, often involving large areas of the body, and are considerably more infectious than patients with a typical rash. The most extreme form is crusted, so-called Norwegian scabies, which was first reported in association with HIV in $1986 . .^{2}$ Treatment failure is frequently encountered when topical scabicides are used to treat crusted scabies, owing to poor penetration of the crusted areas. Ivermectin is an oral alternative to topical treatment that has been successfully used to treat patients with both ordinary and crusted scabies. ${ }^{3-6}$

Six reports of nosocomial transmission of scabies have been published in which the index cases were HIV-infected patients with crusted scabies. ${ }^{7-12}$ In most cases misdiagnosis of the rash predisposed to nosocomial transmission. This report describes an outbreak on an HIV ward that occurred despite immediate diagnosis, and discusses appropriate preventative measures and the response of the index case and a second patient to combined topical treatment and ivermectin.

\section{Case 1: index Case}

The index case was in a 45 year old white homosexual male who was admitted for management of worsening HIV encephalopathy and a rash. He had a previous history of asteatosis with associated eczema. Scabies had been diagnosed 5 months previously and treated with malathion with worsening of the eczema. The CD4+ lymphocyte count was $0.11(\mathrm{NR}=0.35-2.2) \times 10^{9} / 1$. On admission, the patient had widespread papular erythema with excoriations over most of the body with areas of thick crust particularly over the scalp and beard area. Scabies was suspected by the admitting nurses, and the patient was isolated; microscopic examination of skin scrapings treated with $10 \%$ potassium hydroxide subsequently confirmed the diagnosis.

He was treated on days 1 and 3 of admission with topical malathion (Derbac $M$ ). Following this the erythema and itch increased and live scabies mites were found still to be present. Because of the lack of effect of topical treatments and the distress produced by treatment, further topical treatment was delayed for 12 days until most of the crusted areas of skin had been removed with dilute chlorhexidine gluconate solution. Topical applications of carbaryl (Derbac C) on five occasions over the following 14 days failed to clear the infestation. Oral ivermectin $(200 \mathrm{mcg} / \mathrm{kg})$ was then given on a named patient basis, and two courses of topical malathion were applied; subsequent skin scrapings were negative and the general appearances of the skin improved. In total, the patient's admission lasted 51 days, and he was infectious for at least the first 29 days.

\section{Secondary cases}

A total of 19 nursing and medical staff worked on the ward during the index patient's admission, of whom 16 (14 nurses, 2 doctors) had direct physical contact with him. Of the staff with direct patient contact, $14(88 \%)$ developed itching within the first 14 days of his 
admission. None of the other patients on the ward, and none of the three staff who did not have contact with the index patient became symptomatic. In 12 staff itching lesions were limited to the forearms and/or hands. Of the 14 affected staff, 9 were seen by the hospital dermatologists; $2 / 9(22 \%)$ had definite scabies with identification of mites, $2(22 \%)$ had skin scrapings suggestive of scabies with typical egg shells but no mites seen, and $5(56 \%)$ had normal skin scrapings. Several members of staff had empirically treated themselves with scabicides before seeing the dermatologist.

\section{Infection Control Measures}

On admission the index patient was isolated in a single room. Staff attending him wore gloves and plastic aprons to minimise skin to skin contact. When secondary transmission had been confirmed, all symptomatic staff and their partners treated themselves irrespective of parasitological confirmation. Further spread did not occur. The failure of infection control led us to review our policy for dealing with crusted scabies in hospitalised patients.

\section{Changes to our infection control guide- lines resulting from the outbreak}

We now distinguish between crusted and ordinary scabies in our infection control guidelines. Staff and visitors attending patients with crusted scabies now wear gowns rather than aprons, in addition to gloves, until skin scrapings have been shown to be negative. Skin scrapings from the patient are repeated when the patient becomes asymptomatic and again 2 and 4 weeks after treatment. The infectious period is minimised by using both ivermectin and topical scabicides as initial treatment. Staff members who inadvertently have skin to skin contact with a patient with crusted scabies are advised to treat themselves prophylactically with a topical scabicide. Staff members who develop symptoms of rash or itching are seen urgently by the hospital dermatologists.

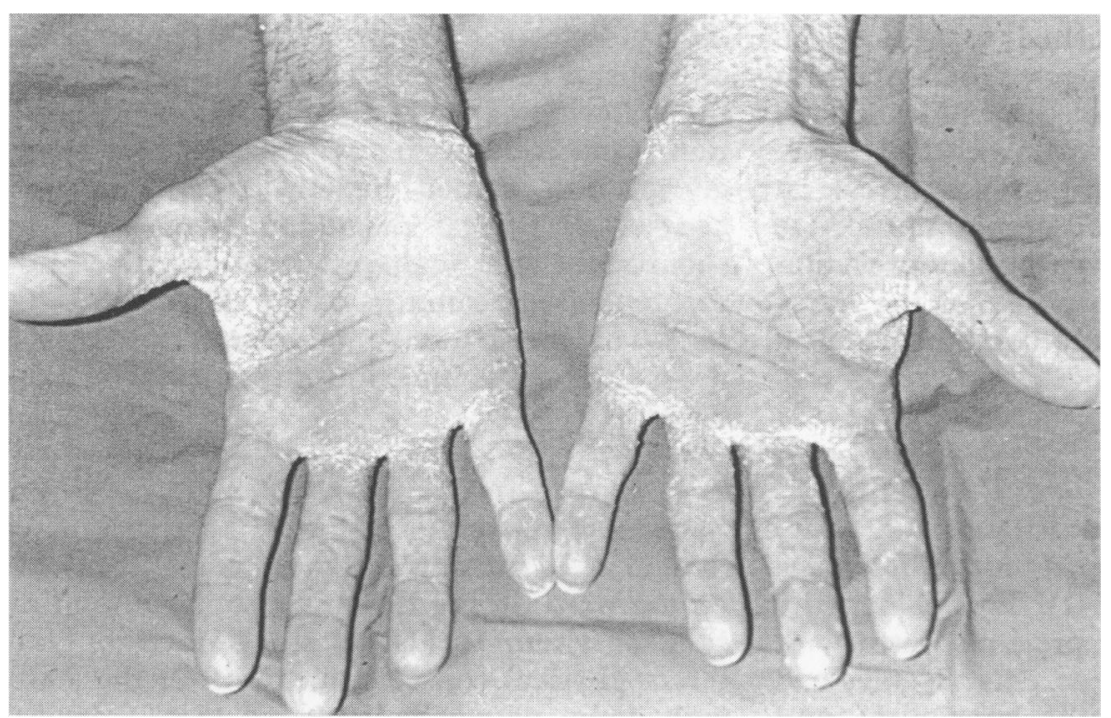

Hands of patient 2 showing crusted scabies.
The patient's room is regularly damp dusted to decrease environmental mites. The patient's linen is treated as infectious.

\section{Case 2}

A 38 year old white homosexual man with $\$$ $\mathrm{CD} 4+$ lymphocyte count of $0.01(\mathrm{NR}=$ $0 \cdot 35-2 \cdot 2) \times 10^{9} / 1$ was admitted with a pruritie papular rash on his trunk and limbs, with crusting on the hands, feet and buttocks (fig) $\stackrel{\mathbb{\Phi}}{\stackrel{\mathbb{Q}}{ }}$ Skin scapings from the hands showed numerous scabies mites. The patient was isolate and treated with oral ivermectin $(120 \mathrm{mcg} / \mathrm{kg})$ together with a topical application of malathion. His itching resolved within $2 \Phi^{2}$ hours and his rash within 10 days of treato ment. The patient was attended by a total of $\frac{0}{80}$ doctors and 9 nurses. No nosocomial trans $\vec{e}$ mission of scabies was attributed to this admission.

\section{Discussion}

Crusted scabies is caused by the same mite Sarcoptes scarbei, that causes typical scabies ing otherwise healthy individuals, and the differ? ence in the two forms results from the hos response. ${ }^{13}$ The highly contagious nature of crusted scabies reflects the high number of mites required to produce the diffuse, erytheso matous, crusted rash. Until the HIV epidemic, crusted scabies was most commonly reporte in elderly patients, many of whom were instio tutionalised and debilitated for a variety of rea sons. HIV infection is an increasingly frequen risk factor. ${ }^{1}$

Nosocomial transmission from HIF seropositive patients with crusted scabies has been reported on a larger scale than the out break described here, with transmission to other patients, relatives, and ancillary staf such as radiographers, laundry staff and $\vec{a}$ chaplain in addition to nurses and doctors. ${ }^{8-}$ iी Crusted scabies is considerably more conta gious than ordinary scabies and brief skin t $\varnothing$ skin contact with a patient who has cruste scabies may be sufficient for transmission t⿳⺈. occur. In addition, patients with crusted scaN bies may remain infectious for long periods because of difficulty eradicating the infestation from heavily crusted areas of skin, even when repeated applications of scabicides are used together with keratolytic agents. The use of oral ivermectin for the treatment of humas ectoparasite infestations is a relatively recen development. ${ }^{3}$ Ivermectin is an effective treat ment of ordinary scabies without the addition of topical agents ${ }^{34}$; however, treatment failure occurred in 1 of 2 patients with crusted scabies and AIDS treated with ivermectin alone. ${ }^{6}$ Ou\& patients tolerated invermectin well, and had rapid response to ivermectin combined witi topical malathion with no recurrence in either case. A rapid response to ivermectin and topical salicylic acid in $2 \mathrm{HIV}$ negative patients with crusted scabies has been recently reported. ${ }^{5}$ At present ivermectin can only be obtained in the UK on a named patient basis.

The extent of our outbreak was probably 
limited by immediate diagnosis and isolation of the patient, but transmission still occurred to staff who had direct contact with him, despite use of aprons and gloves. Forearm skin contact while lifting the patient may have occurred. Of the nine symptomatic staff who were dermatologically assessed, four (44\%) had microscopic evidence of scabies infection. Itching in staff with negative skin scrapings may have been psychological in origin, but in some may have represented allergic reactions to immature mites following prior sensitisation to mite antigens. ${ }^{14}$

The occupational health service must be prepared to investigate outbreaks without delay; this requires rapid access to specialist dermatology services for microscopic confirmation of the diagnosis in early cases. In the case of an established outbreak, treatment of all staff and patients who have had contact with the index case may be warranted, although there are currently no guidelines concerning the treatment of asymptomatic staff, or symptomatic staff without a definite diagnosis. Our experience has been that without such measures concerns remain among ward staff about continued transmission.

The treatment of crusted scabies with topical scabicides often requires multiple applications and early use of ivermectin orally should be considered. Nosocomial transmission of scabies from AIDS patients is a risk, especially on HIV units. The risk of transmission is greatly increased in the case of crusted scabies and guidelines to prevent and respond to nosocomial transmission should be in place.

1 Orkin M. Scabies in AIDS. Sem in Dermatol, 1993;12:9-14 2 Sadick N, Kaplan MH, Pahwa SG, Sarngadharan MG. Unusual features of scabies complicating human T-lymphotrophic virus type III infection. 7 Am Acad Dermatol 1986;15:482-6.

3 Glaziou P, Cartel JL, Briot C, Moulia-Pelat JP, Marty PMV. Comparison of ivermectin and benzyl benzoate for treatment of scabies. Trop Med Parasitol 1993;44:331-2.

4 Marty P, Gari-Toussaint M, Le Fichoux Y, Gaxotte P. Efficacy of ivermectin in the treatment of an epidemic of Efficacy of ivermectin in the treatment of an epidemic
sarcoptic scabies. Ann Trop Med Parisitol 1994;88:453.

5 Aubin F, Humbert P. Ivermectin for crusted (Norwegian) scabies. N Engl f Med 1995;332:612.

6 Meinking TL, Taplin D, Hermida JL, Pardo R, Kerdel FA. The treatment of scabies with ivermectin. N Engl $\mathcal{F}$ Med 1995;333:26-30.

7 Jucowics P, Ramon ME, Don PC, Stone RK, Bamji M. Norwegian scabies in an infant with acquired immunodeficiency syndrome. Arch Dermatol 1989;125:1670-6.

8 Dillon SM. An HIV infected patient with an extraordinary rash. Hospital Practice 1989;24:199-200.

9 Siera J, Romeu J, Ribera M, et al. Hospital outbreak of scabies stemming from two AIDS patients with Norwegian bies stemming from two AIDS

10 Rostami G, Sorg TB. Nosocomial outbreak of scabies associated with Norwegian scabies in an AIDS patient. Internat f STD 1990;1:209-10.

11 Squires J. Scabies: an unusual presentation in a man with AIDS. Clin Cases Dermatol 1990;2:5-9.

12 Moss VA, Salisbury J. Scabies in an AIDS hospice unit. $\mathrm{Br}$ 7 Clin Pract 1990;45:35-6.

13 Cabera R, Agar A, Dahl MV. The immunology of scabies. Sem in Dermatol 1993;12:15-21.

14 Burns DA. An outbreak of scabies in a residential home. $\mathrm{Br}$ f Dermatol 1987;117:359-61. 